heatrelated_illness_and_death_data_methods_and_limita tions. Accessed September 12, 2017.

12. Basu R, Pearson D, Malig B, Broadwin R, Green R. The effect of high ambient temperature on emergency room visits. Epidemiology. 2012;23(6):813-20.

13. Jesdale BM, Morello-Frosch R, Cushing L. The racial/ethnic distribution of heat risk-related land cover in relation to residential segregation. Environ Health Perspect. 2013; 121(7):811-7.

\section{In Response to AVReCh-Avalanche Resuscitation Checklist by Strapazzon et al}

\section{To the Editor:}

With increasing participation in winter sports, there has been increased exposure to avalanche danger. Thus, the baseline knowledge of the Avalanche Victim Resuscitation Checklist (AVReCh) proposed by the International Commission for Mountain Emergency Medicine and its spread among health care providers and mountain rescue personnel is fundamental. For that reason, we recently introduced in our continuing medical education course "La gestione del trauma in DEA (Dipartimento di Emergenza ed Accettazione)" (A.O.S. Croce e Carle Cuneo) specific training on this topic, and we read the brief report by Strapazzon et $\mathrm{al}^{1}$ with interest.

As Strapazzon et al report, participants included both novice and expert medical professionals, such as physicians, nurses, and mountain rescue personnel, and laypersons (nonmedical/nonrescue persons). Of a total of 193 surveys analyzed, only $34 \%$ of the participants possessed knowledge of the AVReCh before the lecture proposed. This result is very interesting but probably not representative of the general population. Unfortunately, this result could be affected by a selection bias because the 8 mountain medicine courses were organized by either the Corpo Nazionale Soccorso Alpino e Speleologico (the Italian Mountain Rescue Society) or Società Italiana Medicina di Montagna (the Italian Society of Mountain Medicine). As such, the participants are all mountain lovers, so if the authors found such a lack of knowledge about the AVReCh among study participants we might expect a lower percentage in a "statistically normal" group.

It could be interesting to use the same survey to determine the level of knowledge about the AVReCh among emergency medicine physicians and nurses who work in areas with potential involvement in a mountain rescue operation. Likewise, those healthcare providers in emergency departments responsible for the downstream care of a patient evacuated from mountain areas in the North of Italy could be surveyed regarding this matter.

Bartolomeo Lorenzati, MD

Andrea Sciolla, MD

Andrea Tortore, MD

Giuseppe Lauria, MD

Emergency Medicine, A.O.S. Croce e Carle, Cuneo, Italy

\section{Reference}

1. Strapazzon G, Migliaccio D, Fontana D, Stawinoga AE, Milani M, Brugger H. Knowledge of the avalanche victim resuscitation checklist and utility of a standardized lecture in Italy. Wilderness Environ Med. 2018;29(1):56-60.

\section{In Reply to Lorenzati et al}

\section{To the Editor,}

We thank Lorenzati et al for their valuable comments. ${ }^{1}$ We agree that the survey participants are part of a selected sample. Most of the survey participants were either advanced life support or basic life support providers or members of mountain rescue services. ${ }^{2}$ The regions of Italy where the survey was held 1) have helicopter emergency medical service specialized in search-and-rescue missions with a mountain rescue technician as part of the team, and 2) host areas of Italian Alps and Apennines where the medical and mountain rescue personnel are at risk of being involved in the management of avalanche patients on site or in the hub/spoke hospitals, ${ }^{3}$ including the authors' institutions. Providers operating in such areas should be able, especially if an avalanche victim is found in cardiac arrest, to administer proper pre- and in-hospital management and triage based on the duration of complete burial (or core temperature), presence of vital signs, airway status, and data about the air pocket. Even if the courses were opened to participants from all areas of Italy, most of the survey participants were operating in these areas.

Avalanche recommendations and tools such as the Avalanche Victim Resuscitation Checklist, in combination with a dedicated education programs, can improve knowledge and good clinical practice regarding principles of avalanche management. ${ }^{4}$ However, dissemination should be adapted to different emergency medical service systems, and surveillance of outcome measures 